\title{
Design of Simple and Double Ridge Waveguide T-Coupler for Space Domain
}

\author{
Fayza Bousalah, Nour Eddine Boukli Hacene
}

Department of Telecommunications, Faculty of Technology, Abou Bakr Belkaid University, Tlemcen, Algeria

Email address:

bousalah.fayza@gmail.com (F. Bousalah),bouklin@yahoo.com (N. E. B. Hacene)

\section{To cite this article:}

Fayza Bousalah, Nour Eddine Boukli Hacene. Design of Simple and Double Ridge Waveguide T-Coupler for Space Domain. Advances in Applied Sciences. Vol. 4, No. 3, 2019, pp. 78-87. doi: 10.11648/j.aas.20190403.12

Received: January 3, 2019; Accepted: February 7, 2019; Published: September 17, 2019

\begin{abstract}
The T-Coupler or the magic tee (or magic T or hybrid tee) is a hybrid or $3 \mathrm{~dB}$ coupler used in microwave systems. It is an alternative to the rat-race coupler. In contrast to the rat-race, the three-dimensional structure of the magic tee makes it less readily constructed in planar technologies such as micro strip or strip line. The magic tee was originally developed in World War II, and first published by W. A. Tyrell of Bell Labs in a 1947 IRE paper. Robert L. Kyhl and Bob Dicke independently created magic tees around the same time. This paper illustrates simple and double ridge waveguide T-coupler. The relationships between the scattering variables in this sort of network are fixed by the unitary condition. Such a network has the properties that it is a matched device with one adjacent port decoupled from any incident port. The object of this paper is to present some results of simulation on the coupling and directivity of double ridge cross-waveguide couplers in a field ridge waveguide. This results are obtain by Ansoft HFSS using the Finite Element Method (FEM) calculations and the Genetic Algorithms method, and which show good performance.
\end{abstract}

Keywords: Simple and Double Ridge Waveguide, T-Coupler, Optimization, HFSS Software, Genetic Algorithm Method, EFM Method, E-Plane, H-Plane

\section{Introduction}

The simple and the double ridge waveguide T-coupler is 4 ports, 180 degree hybrid splitter, realized in field waveguide. Like all of the coupler and splitter structures, the simple and the double ridge waveguide T-coupler can be used as a power combiner, or a divider. It is ideally lossless, so that all power into one port can be assumed to exit the remaining ports.

The magic tee is a combination of $\mathrm{E}$ and $\mathrm{H}$ plane tees. Arm 4 forms an H-plane tee with arms 1 and 2. Arm 4 forms an Eplane tee with arms 1 and 2. Arms 1 and 2 are sometimes called the side or collinear arms. Port 3 is called the H-plane port, and is also called the $\Sigma$ port, sum port or the P-port (for "parallel"). Port 4 is the E-plane port, and is also called the $\Delta$ port, difference port, or $S$-port (for "series"). There is no one single established convention regarding the numbering of the ports.

To function correctly, the ridge waveguide T-coupler or the magic tee must incorporate an internal matching structure. This structure typically consists of a post inside the H-plane tee and an inductive iris inside the E-plane limb, though many alternative structures have been proposed. Dependence on the matching structure means that the magic tee will only work over a limited frequency band.

This paper illustrates a well-known and commonly used high frequency device. The main idea behind the simple and the double ridge waveguide T-coupler is to combine a TE and a TM waveguide splitter. In this particular case port 2 and port 3 are de-coupled, so one can expect $S_{23}$ and $S_{32}$ to have very low values. Viewing the electric fields gives a better understanding how the «Simple and Double Ridge Waveguide T-Coupler» works $[1,2]$.

\section{Operation of Simple and Double Ridge Waveguide T-Coupler}

The 3 ports ridge waveguide T-coupler is a classic component in microwave engineering. It is defined as a matched 3 ports network with one adjacent port decoupled from any input port, it's illustrated in (figure 1). 


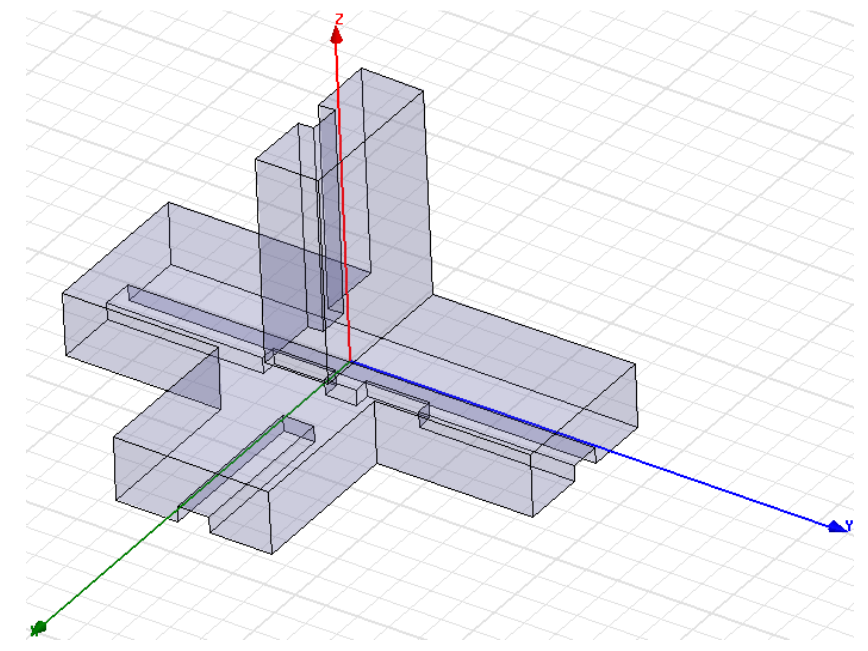

Figure 1. Schematic diagrams of 4 ports of simple ridge waveguide $T$ coupler.

The ridge waveguide T-coupler is derived from the way in which power is divided among the various ports. A signal injected into the H-plane port will be divided equally between ports 1 and 2, and will be in phase. A signal injected into the E-plane port will also be divided equally between ports 1 and 2, but will be 180 degrees out of phase. If signals are fed in through ports 1 and 2, they are added at the $\mathrm{H}$ plane port and subtracted at the E-plane port. Thus, with the ports numbered as shown, and to within a phase factor, the full scattering matrix for an ideal waveguide $\mathrm{T}$-coupler or magic tee is given in the usual way by:

$$
[S]=\left(\begin{array}{llll}
S 11 & S 12 & S 13 & S 14 \\
S 21 & S 22 & S 23 & S 24 \\
S 31 & S 32 & S 33 & S 34 \\
S 41 & S 42 & S 43 & S 44
\end{array}\right)
$$

Because of H-plane Tee section,

$$
\mathrm{S} 23=\mathrm{S} 13
$$

Because of E-plane Tee section,

$$
\mathrm{S} 24=-\mathrm{S} 14
$$

Because of geometry of the junction on inputs at port 3 can't come out of port 4 since they are isolated ports and vice-versa $\Rightarrow$

$$
\mathrm{S} 34=\mathrm{S} 43=0
$$

From symmetric property $\mathrm{Sij}=\mathrm{Sji}$ :

$$
\begin{aligned}
& \mathrm{S} 12=\mathrm{S} 21 ; \mathrm{S} 13=\mathrm{S} 31 ; \\
& \mathrm{S} 23=\mathrm{S} 32 ; \mathrm{S} 34=\mathrm{S} 43 ; \\
& \mathrm{S} 24=\mathrm{S} 42 ; \mathrm{S} 41=\mathrm{S} 14 ;
\end{aligned}
$$

If ports 3 and 4 are perfectly matched to the junction:

$$
\mathrm{S} 33=\mathrm{S} 44=0
$$

Substitute above properties in equation (1)

$$
\begin{gathered}
{[S]=\left(\begin{array}{c}
S 11 S 12 S 13 S 14 \\
S 12 S 22 S 13-S 14 \\
S 13 S 1300 \\
S 14-S 1400
\end{array}\right)} \\
{[S]=\left(\begin{array}{c}
S 11 S 12 S 13 S 14 \\
S 12 S 22 S 13-S 14 \\
S 13 S 1300 \\
S 14-S 1400
\end{array}\right)}
\end{gathered}
$$

From unity matrix property,

$$
\begin{aligned}
& {[\mathrm{s}] \cdot[\mathrm{s}]^{*}=[\mathrm{I}] \Rightarrow[S]=\left(\begin{array}{c}
S 11 S 12 S 13 S 14 \\
S 12 S 22 S 13-S 14 \\
S 13 S 1300 \\
S 14-S 1400
\end{array}\right)}
\end{aligned}
$$

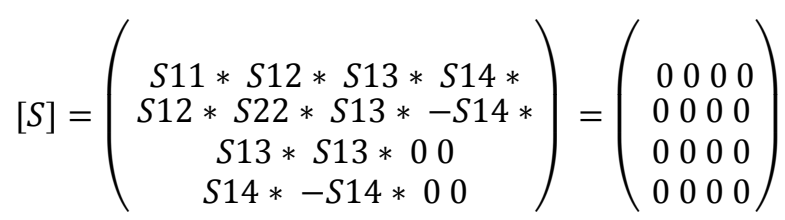

$$
\begin{aligned}
& \mathrm{R} 1 \mathrm{c} 1:-|\mathrm{s} 11|^{2}+|\mathrm{s} 12|^{2}+|\mathrm{s} 13|^{2}+|\mathrm{s} 14|^{2}=1 \\
& \mathrm{R} 2 \mathrm{c} 2:-|\mathrm{s} 12|^{2}+|\mathrm{s} 22|^{2}+|\mathrm{s} 13|^{2}+|\mathrm{s} 14|^{2}=1 \\
& \text { R3c3:- }|\mathrm{s} 13|^{2}+|\mathrm{s} 13|^{2}=1 \\
& \mathrm{R} 4 \mathrm{c} 4:-|\mathrm{s} 14|^{2}+|\mathrm{s} 14|^{2}=1
\end{aligned}
$$

From equation 10 and 11:

$$
\begin{aligned}
& \mathrm{S} 13=1 / \sqrt{ } 2 \\
& \mathrm{~S} 14=1 / \sqrt{ } 2
\end{aligned}
$$

Comparing equation (8) and (9) we get:

$$
\mathrm{S} 11=\mathrm{S} 22
$$

Using these values from equation (12) and (13) in equation (8), we get:

$$
\begin{gathered}
|\mathrm{s} 11|^{2}+|\mathrm{s} 12|^{2}+1 / 2+1 / 2=1 \\
\Rightarrow|\mathrm{s} 11|^{2}+|\mathrm{s} 12|^{2}=0
\end{gathered}
$$

We know that:

$$
\mathrm{S} 11=0 \text { hence } \mathrm{S} 12=0
$$

$$
\text { So from equation (9) and } \mathrm{S} 22=0
$$

This means port 1 and port 2 are also perfectly matched to the junction. Hence in any four ports junction, if any two ports are perfectly matched to the junction then the remaining two are automatically matched to the junction such a junction where in all the four ports are perfectly matched to the junction is a ridge waveguide T-Coupler.

$$
S=\frac{1}{\sqrt{2}}\left(\begin{array}{cccc}
0 & 0 & 1 / \sqrt{2} & 1 / \sqrt{2} \\
0 & 0 & 1 / \sqrt{2} & -1 / \sqrt{2} \\
1 / \sqrt{2} & 1 / \sqrt{2} & 0 & 0 \\
1 / \sqrt{2} & -1 / \sqrt{2} & 0 & 0
\end{array}\right)
$$

We know that, $[\mathrm{b}]=[\mathrm{s}]$. [a] 


$$
\begin{gathered}
\mathrm{b} 1=1 / \sqrt{ } 2(\mathrm{a} 3+\mathrm{a} 4) \\
\mathrm{b} 2=1 / \sqrt{ } 2(\mathrm{a} 3-\mathrm{a} 4)(18) \\
\mathrm{b} 3=1 / \sqrt{ } 2(\mathrm{a} 1+\mathrm{a} 2) \\
\mathrm{b} 4=1 / \sqrt{ } 2(\mathrm{a} 1-\mathrm{a} 2)
\end{gathered}
$$

From equation (18):

$$
\begin{aligned}
& \text { Case } 1: a 4 \neq 0, a 1=a 2=a 4=0 \\
& b 1=a 3 / \sqrt{ } 2 \\
& b 2=a 3 / \sqrt{ } 2 \\
& b 3=0 \\
& \text { b4=0 --- satisfies property of } H \text {-plane Tee } \\
& \text { Case } 2:, a 3 \neq 0 \text { a } 1=a 2=a 3=0 \\
& b 1=a 4 / \sqrt{ } 2 \\
& \text { b2 }=-a 4 / \sqrt{ } 2 \\
& \text { b3 }=0 \\
& \text { b4 }=0 \text {--- satisfies property of E-plane Tee } \\
& \text { Case } 3: a 1 \neq 0, a 2=a 3=a 4=0 \\
& \text { b1 }=0 ; \\
& \text { b2 }=0 ; \\
& \text { b3 }=a 1 / \sqrt{ } 2 ; \\
& \text { b4 }=a 1 / \sqrt{ } 2 ;
\end{aligned}
$$

That is, when power is fed into the port 1 nothing comes out of port 2 and vice-versa even though they are collinear ports (MAGIC) Hence they are isolated ports.

Case 4: $\mathrm{a} 3=\mathrm{a} 4, \mathrm{a} 1=\mathrm{a} 2=0$

So we have,

$\mathrm{b} 1=1 / \sqrt{ } 2(2 \mathrm{a} 3)$;

$\mathrm{b} 2=0$;

$\mathrm{b} 3=0$;

$\mathrm{b} 4=0$;

Case 5: $\mathrm{a} 1=\mathrm{a} 2, \mathrm{a} 3=\mathrm{a} 4=0$ (ADDITIVE PROPERTY)

So we have,

$\mathrm{b} 1=0$;

$\mathrm{b} 2=0$;

$\mathrm{b} 3=1 / \sqrt{ } 2(2 \mathrm{a} 3)$;

$\mathrm{b} 4=0$;

Equal inputs at port (1) and (2) results in on outputs at port (3) and no output at $1,2 \& 4$.

\section{Simulation and Optimisation of Simple and Double Ridge Waveguide T-Coupler}

Opposing polarities as it splits between ports 2 and 3. The interior dimensions of the waveguide are $50 \mathrm{~mm}$ by $20 \mathrm{~mm}$. This is not a standard waveguide size. You can tell that Ansoft is run by mathematicians, not microwave engineers, or they would have picked a "real" waveguide band. Below is the model show in figures 2 and 3.

\subsection{Simulation of Simple and Double Ridge Waveguide T-Coupler}

The simulator of structures high frequency of Ansoft HFSS (High Frequency Structural Simulator) is a software package (EM) electromagnetic double alternation allowing the electromagnetic calculation of a structure in $3 \mathrm{D}$ and the different proprieties as discontinuities [4], fields, and propagations. HFSS is used in several electromagnetic fields and in particular in the field of Telecommunications for the simulation of satellites antennas. A double ridge crosswaveguide directional coupler has been designed for feeding RF power.

Port match at E plane arm has been achieved through inductive iris which cancels out capacitive discontinuity in this arm of the Tee. Capacitive post has been utilized in the $\mathrm{H}$ arm of the Tee to achieve port matches in this arm. Further improvement in the port return loss (better than $50 \mathrm{~dB}$ ) has been achieved by utilizing a conical post in the main waveguide line. This has helped in achieving port return loss of better than $50 \mathrm{~dB}$ at all ports. The isolation parameters obtained from these simulations are better than $90 \mathrm{~dB}$ between port 3 and 4 whereas it is better than $60 \mathrm{~dB}$ for port 1 and 2 .

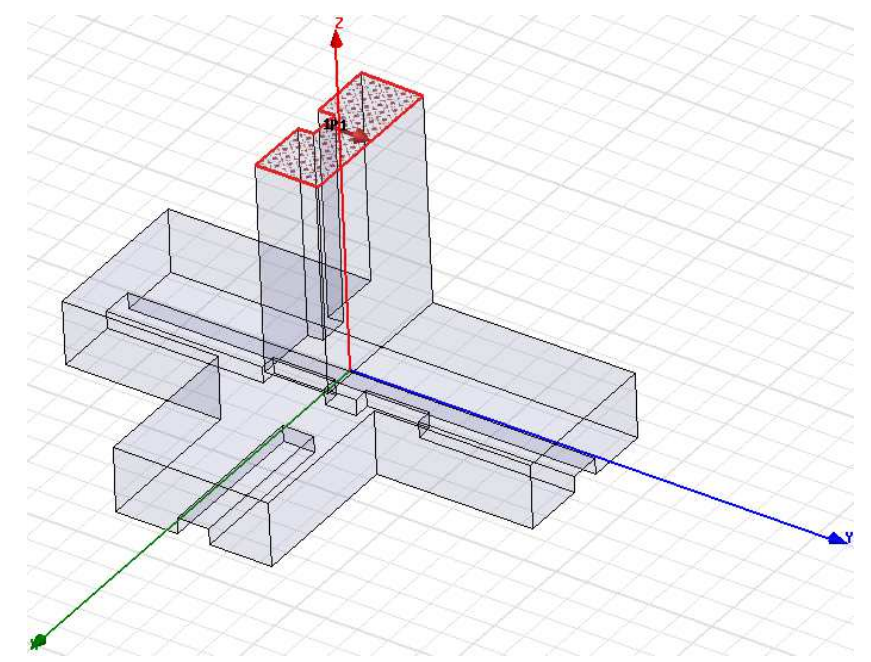

Figure 2. 3D model for simple ridge waveguide T-coupler.

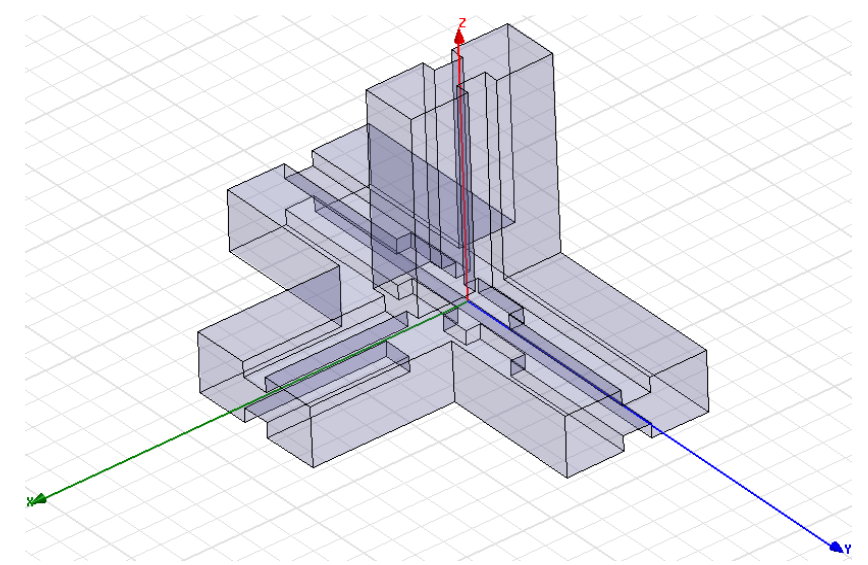

Figure 3. 3D model for double ridge waveguide T-coupler.

\subsection{Simulation of Simple and Double Ridge Waveguide T-Coupler}

The application of the Genetic Algorithm "AGs" [5], enables us to solve the problem of synthesis of the 
waveguides coupler "Double ridge cross-waveguide bidirectional coupler".

In our application, we put forward the characteristics of AGs in their applications to optimization [6] the dimensions of the double ridge cross-waveguide bidirectional coupler.

In fact, many parameters influence the solution of the problem by the genetic algorithm. After several tests, we noted that a good precision with a relatively acceptable computing time are obtained by applying the following parameters:

a. Number of individuals: 30 .

b. Number of generations: 100 .

c. Probability of mutation: 0.02 .

d. Probability of crossing: 0.8 .

e. Coding of 16 bits.

f. Select by Russian roulette.

g. Tolerance error $=0.001 . \varepsilon$.

h. Terminals variations [3.5 to 6] GHz.

\subsubsection{Simulation and Optimization of Simple Ridge Waveguide T-Coupler}

The figure 4 represents the simple ridge waveguide $\mathrm{T}$ coupler. The dimensions of the structures are given by:

a. Lenght of guide: $\mathrm{L}=50 \mathrm{~mm}$

b. Width of guide: $1=50 \mathrm{~mm}$

c. Height of guide: $\mathrm{h}=20 \mathrm{~mm}$.

d. Length of the ridge: $\mathrm{Ln}=50 \mathrm{~mm}$

e. Width of the ridge: $\ln =15 \mathrm{~mm}$

f. Thickness of the ridge: $\mathrm{hn}=10 \mathrm{~mm}$

g. Band of frequency de [1-5] Ghz.

After optimization of the structure, the new dimensions of the ridges for the 4 access of the T-coupler are given by:
$\mathrm{Ln}=50 \mathrm{~mm}, \mathrm{ln}=13.56 \mathrm{~mm}, \mathrm{hn}=9.44 \mathrm{~mm}$.

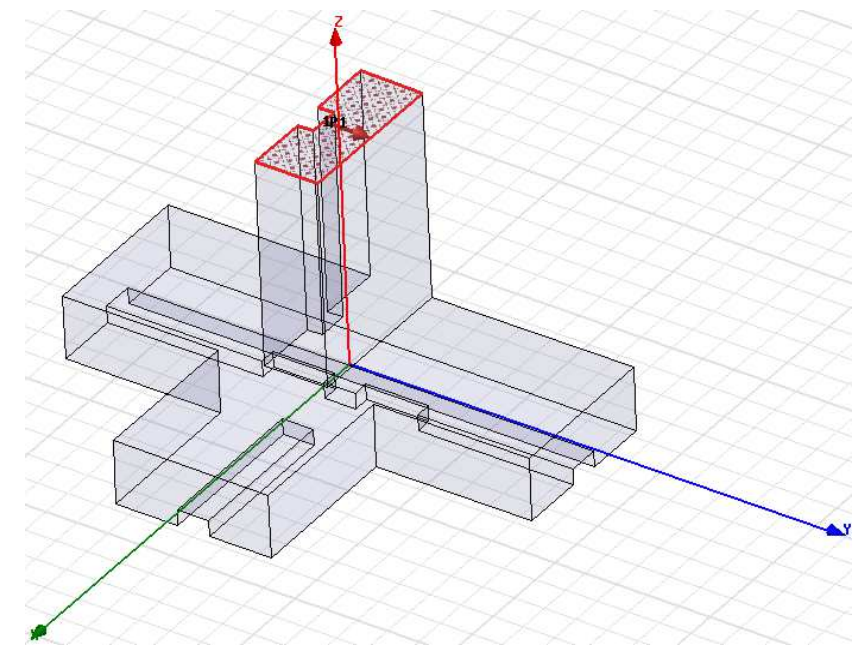

Figure 4. Structure of simple ridge waveguide T-coupler.

Figure 5 shows the variations of the various S-parameters as a function of frequency. The reflection coefficient $S_{11}$ (in red color) is equal to $-8 \mathrm{~dB}$, the transmission coefficients $S_{12}$ (in light purple color) and $\mathrm{S}_{13}$ (in dark purple color), which are equal to $-3.5 \mathrm{~dB}$ and $-4.5 \mathrm{~dB}$, respectively. $\mathrm{S}_{14}$ isolation (in blue color) that is equal to $-18.60 \mathrm{~dB}$ at $-21 \mathrm{~dB}$ in the frequency band of [1-5] Ghz, so there is a weak signal transmission at port 4 , it is almost isolated. Based on the simulation results, there is good signal transmission at port 2 and 3. There are small losses that result from reflection at port 1. [11]

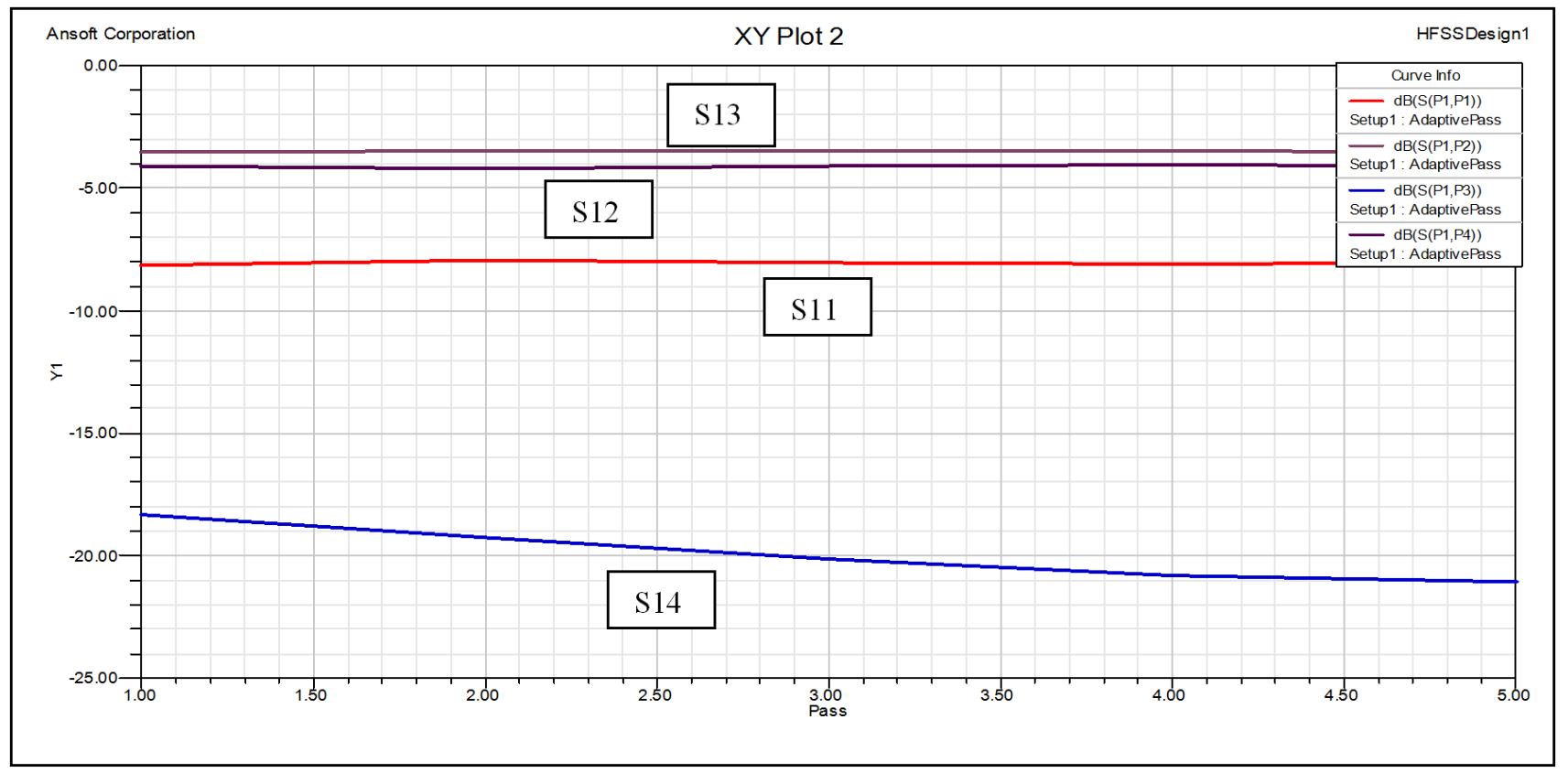

Figure 5. S-parameters (Coefficient of reflection S11 and coefficient of transmission S21) as a function of frequency.

The figures 6 and 7 show the propagation of the electric field $\mathrm{E}$ and the magnetic field $\mathrm{H}$ respectively. 


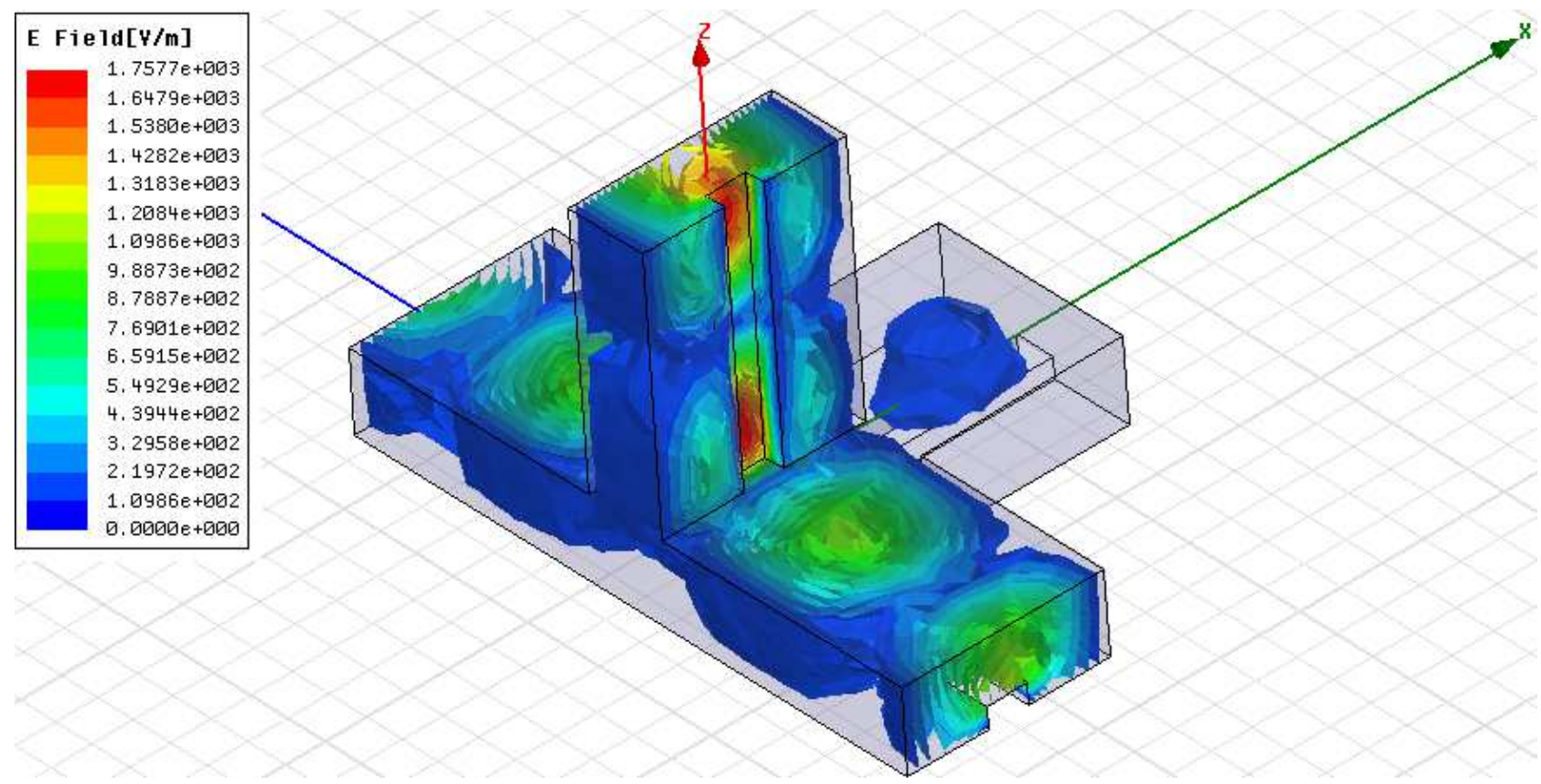

Figure 6. Propagation of the electric field E.

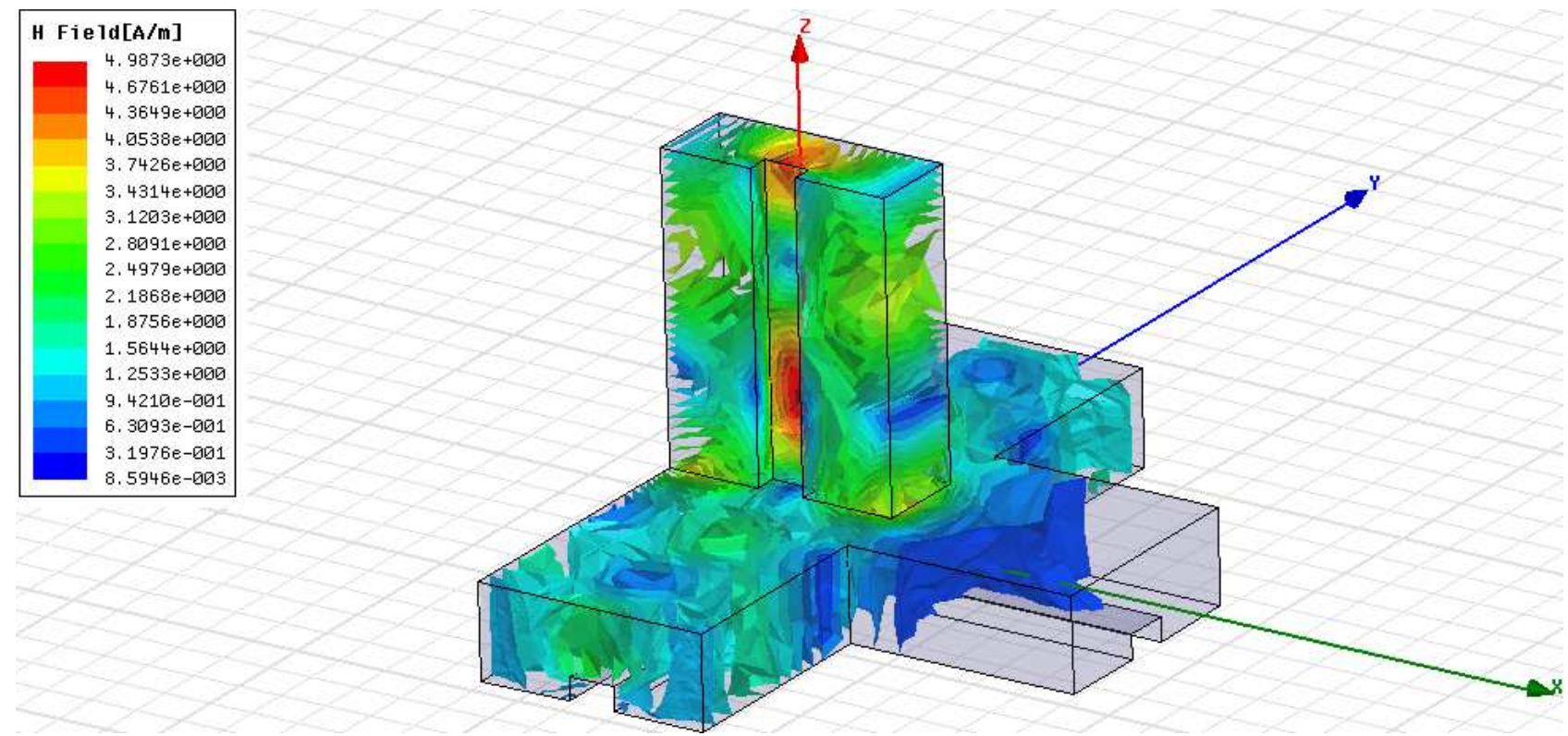

Figure 7. Propagation of the magnetic field $H$.

It can be seen that the propagation of the $\mathrm{E}$ and $\mathrm{H}$ fields is more intense inside the rib, whereas the fields weaken as they move away from the rib. For port 4, the fields are null. [11]

\subsubsection{Simulation and Optimization of Double Ridge Waveguide T-Coupler}

The figure 8 represents double ridge waveguide T-coupler. The dimensions of the structures are given by:

a. Lenght of guide: $\mathrm{L}=50 \mathrm{~mm}$

b. Width of guide: $1=50 \mathrm{~mm}$ c. Height of guide: $\mathrm{h}=20 \mathrm{~mm}$.

d. Length of the ridge: $\mathrm{Ln}=50 \mathrm{~mm}$

e. Width of the ridge: $\ln =15 \mathrm{~mm}$

f. Thickness of the ridge: $\mathrm{hn}=10 \mathrm{~mm}$

g. Band of frequency de [1-5] Ghz.

After optimization of the structure, the new dimensions of the ridges for the 4 access of the T-coupler are given by: $\mathrm{Ln}=$ $50 \mathrm{~mm}, \mathrm{ln}=13.56 \mathrm{~mm}, \mathrm{hn}=9.44 \mathrm{~mm}$. 


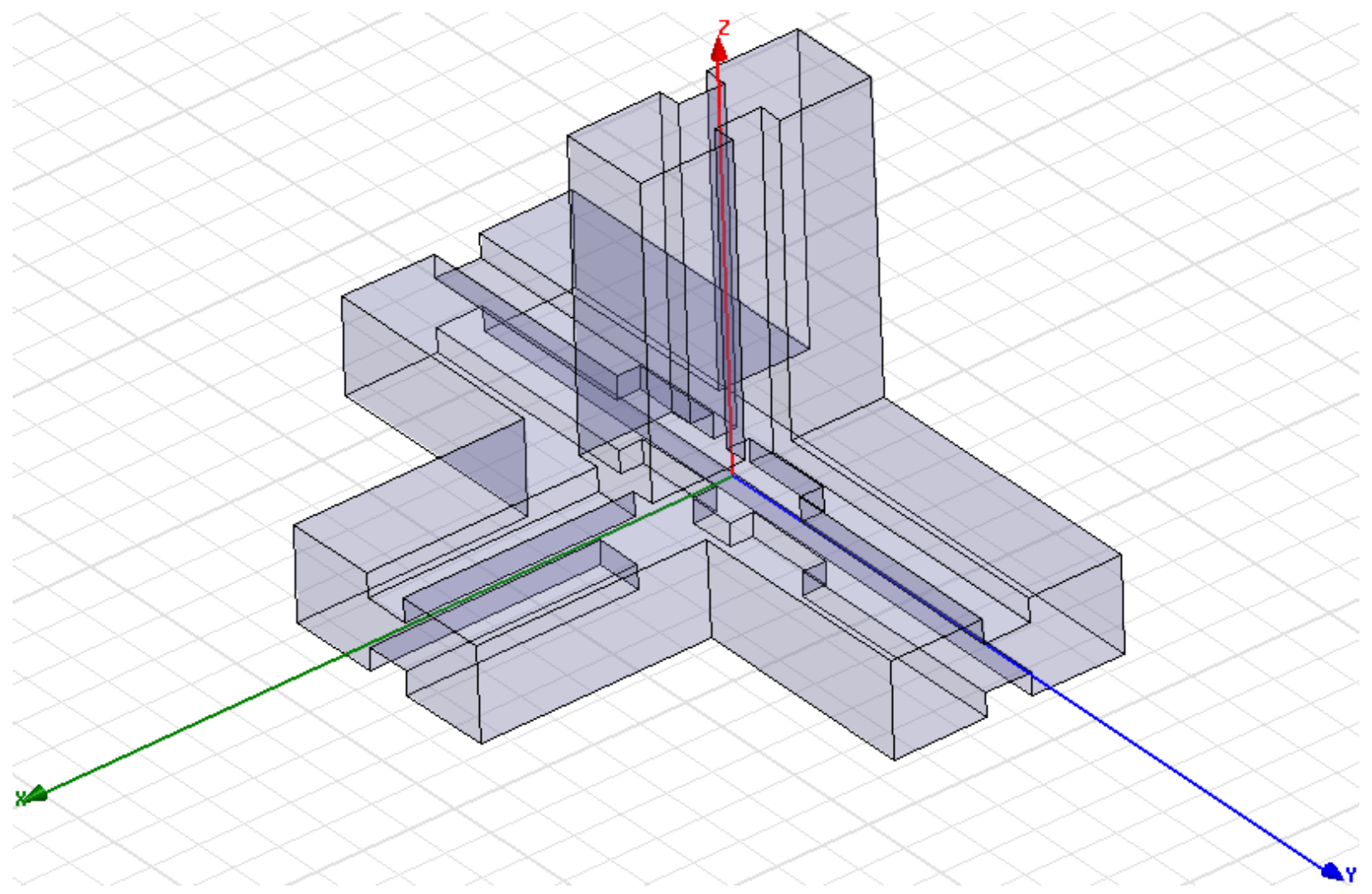

Figure 8. Design on $3 D$ of double ridge waveguide T-coupler.

The figures 9 and 10 show the propagation of the electric field $\mathrm{E}$ and the magnetic field $\mathrm{H}$ respectively.

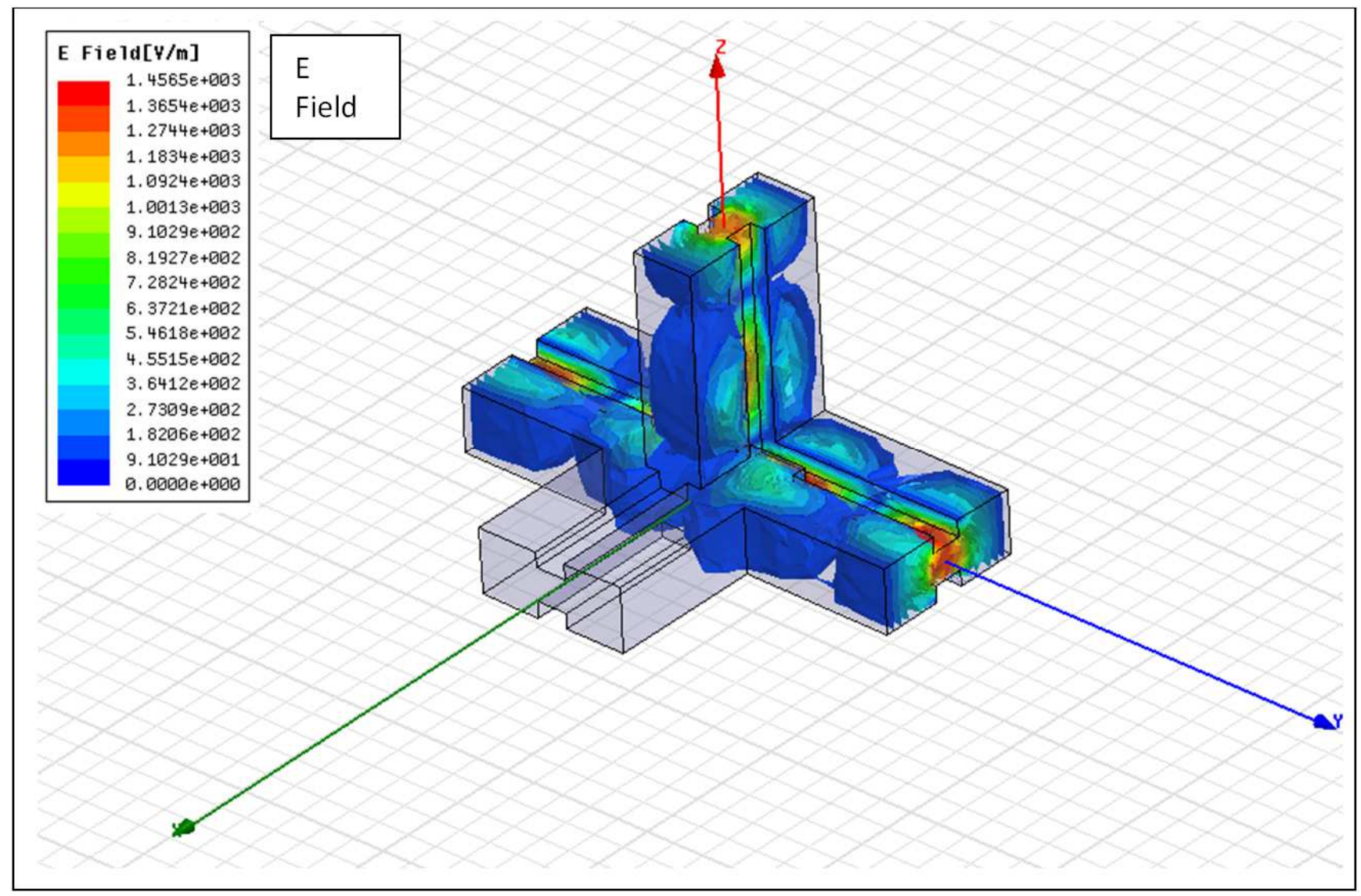

Figure 9. Propagation of the electric field E. 


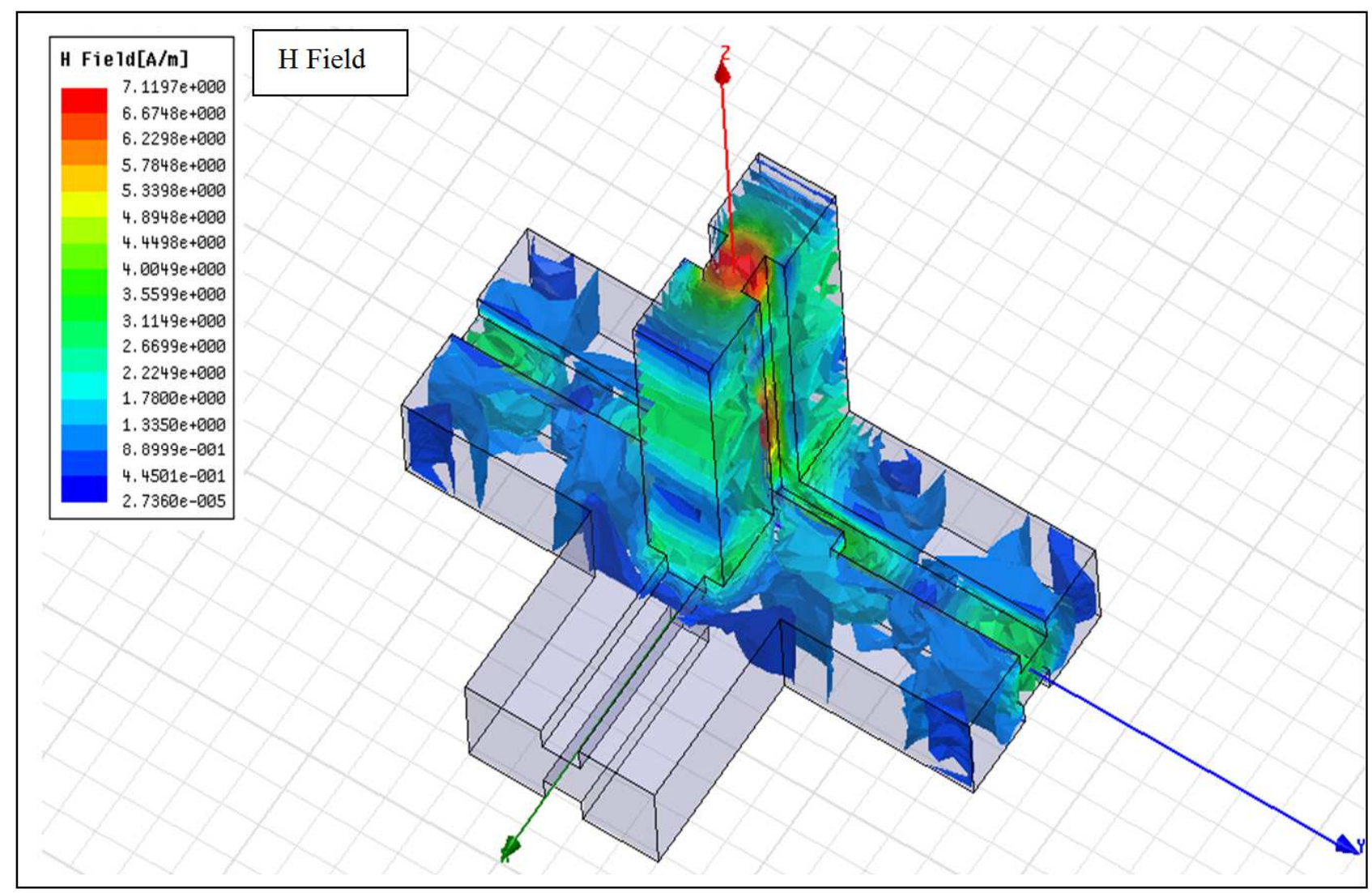

Figure 10. Propagation of the magnetic field $\mathrm{H}$.

Note that the propagation of the E-field is higher inside the ribs on either side of the guide for the 3 ports, whereas the propagation of the $\mathrm{H}$-field is more intense at the rib of the port of entry (port1). We also note that the fields weaken away from the ribs. For port 4, the fields are null. [11]

The figure 11 shows the variations of the various S-parameters as a function of frequency.

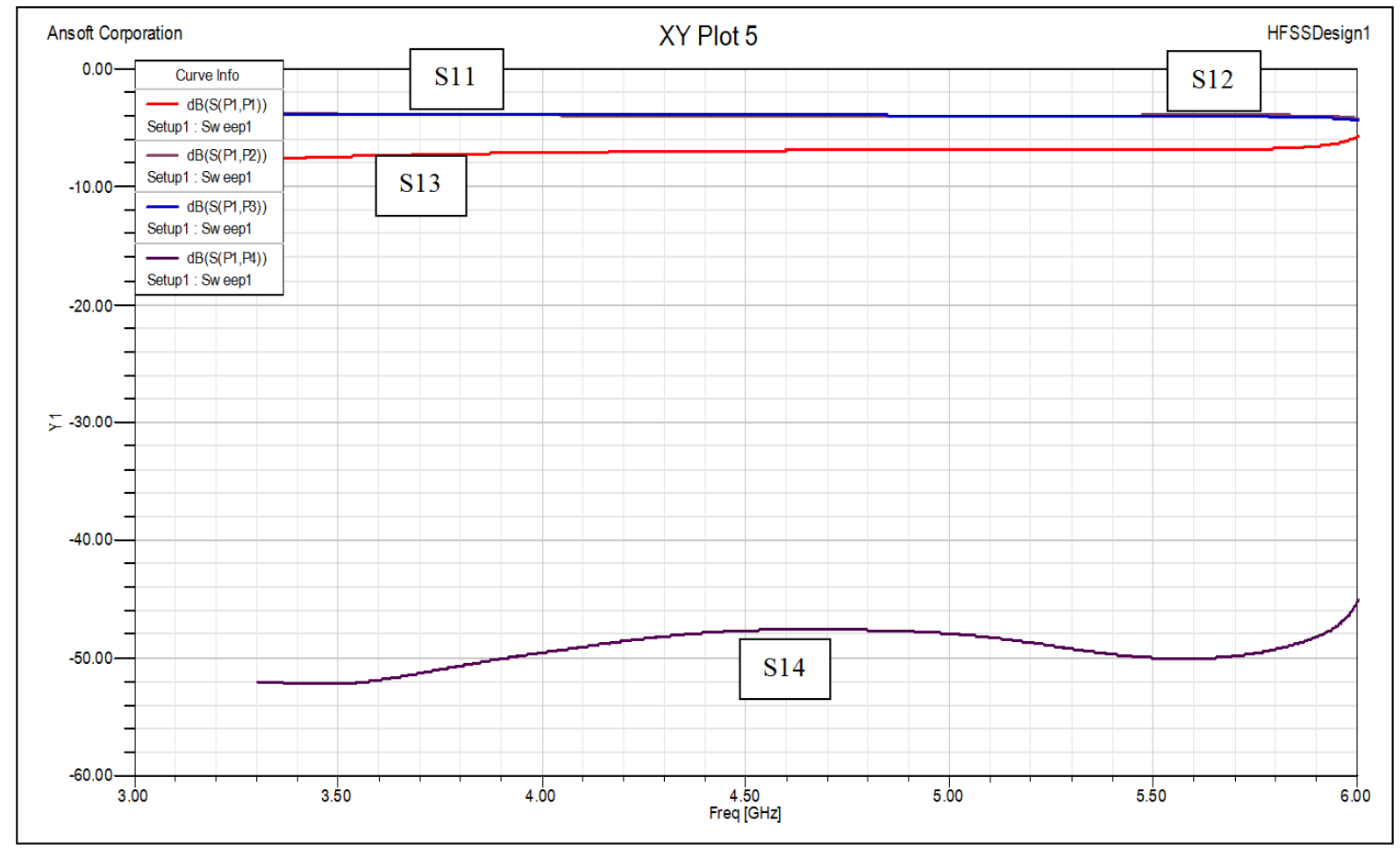

Figure 11. Different S-parameters as a function of frequency. 
The reflection coefficient $\mathrm{S}_{11}$ is equal to $-6 \mathrm{~dB}$ (in light purple color), we note low reflection losses through port 1. The transmission coefficients $\mathrm{S}_{12}$ (in red color) and $\mathrm{S}_{13}$ (in bleu color) are equal to $-3 \mathrm{~dB}$, the insulation coefficient $\mathrm{S}_{14}$ is equal to $-49 \mathrm{~dB}$ (in dark purple color), and so there is no signal transmission. According to the simulation results, there is good signal transmission, there are small losses that result from reflection and port 4 is completely isolated. [11]

\section{Compareson of Simple and Double Ridge Waveguide T-coupler}

An Ideal magic tee or hybrid tee is a 4-port microwave passive reciprocal device and is a combination of $\mathrm{E}$ and $\mathrm{H}$ plane tees. Out of four arms the two side arms are called as collinear arms and remaining two are $\mathrm{H}$ and $\mathrm{E}$ arms (port 1 and 4), which are crossed polarized or electromagnetically decoupled from each other. If power is fed in $\mathrm{H}$ arm (port 4), it will be equally divided in phase to two side arms and if power is fed in E arm (port 1) it will be equally divided out of phase. Similarly if the collinear arms will be fed equal powers, these will be added at port 4 and subtracted at port 1 . The magic tee is commonly used for duplexing, mixing and impedance measurement in high frequency structures. The structure of a conventional magic tee is shown in (figure 12). The Magic Tee in X band [10] has been designed using HFSS software (figure 13) in which port 2 and port 3 has been assigned to two collinear arms, whereas port 1 and port 4 for $\mathrm{E}$ and $\mathrm{H}$ arm respectively.

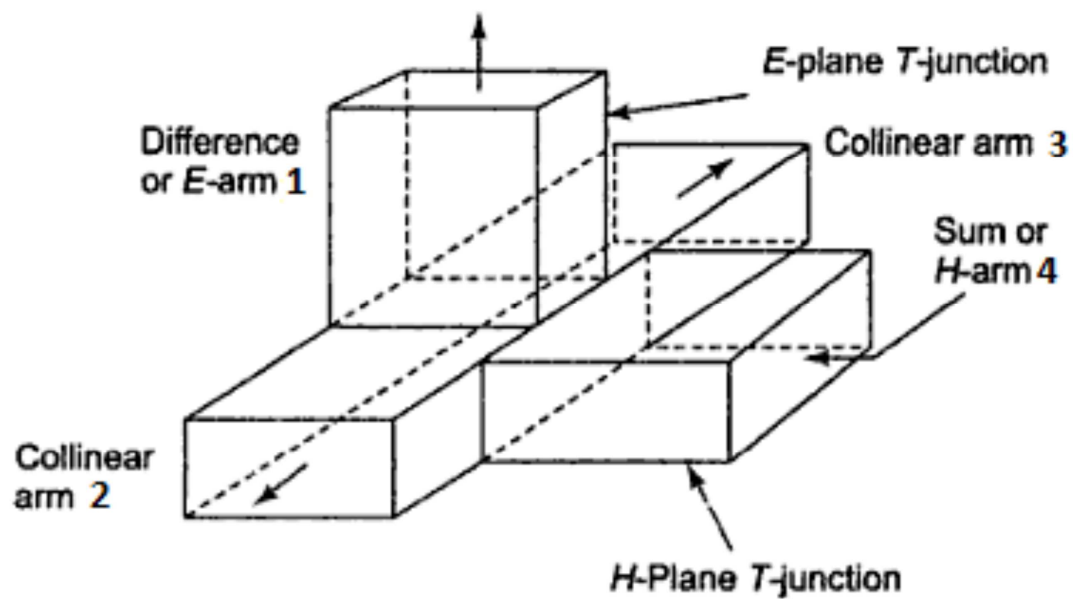

Figure 12. Structure of the Conventional Magic Tee.

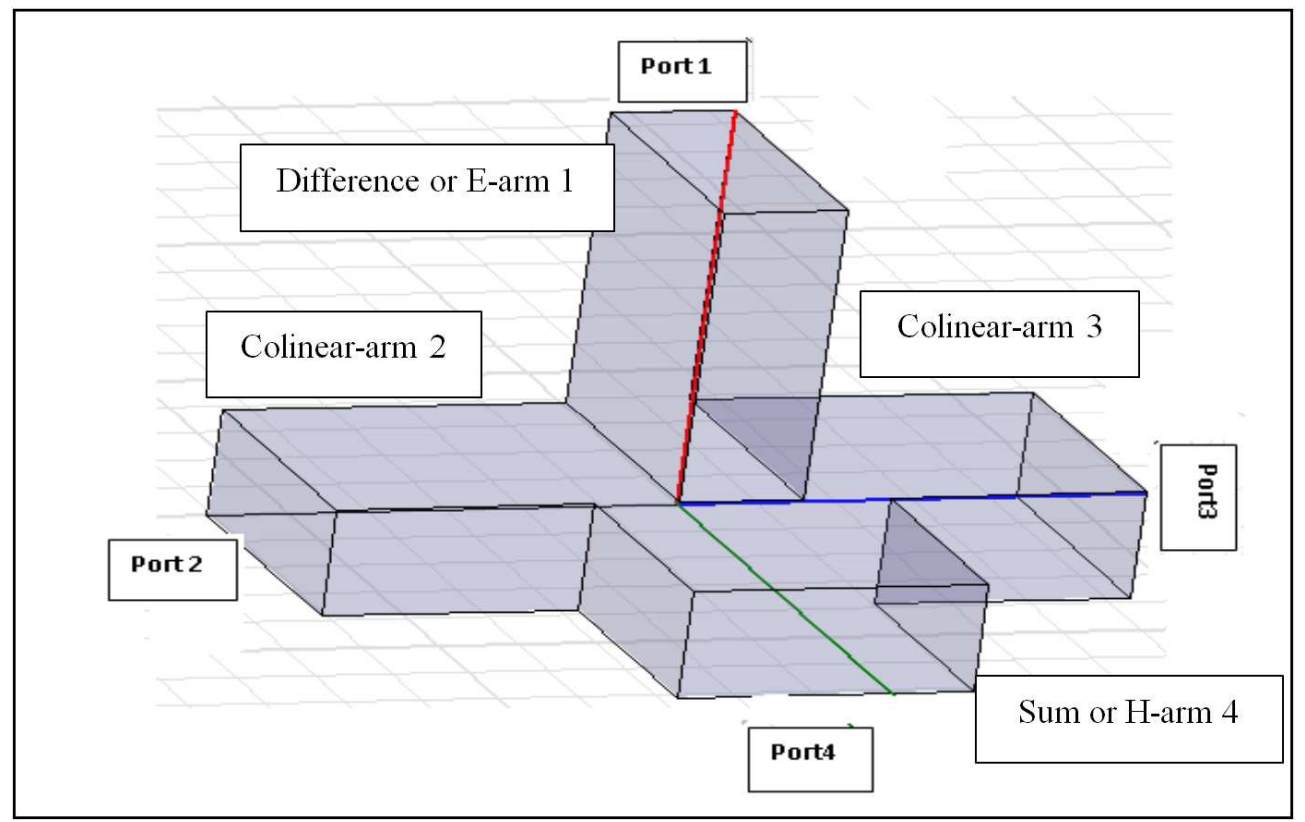

Figure 13. Diagram of Magic Tee using HFSS.

The figure 14 shows the phase of transmission coefficient between port 2 and 3 when signal entering at port 1 . It can easily be stated from the figure that when signal entering port 1, it will equally divide and appear at port 2 and 3 with opposite phase 
of the magic-tee structure. The difference is of 180 degree. It's the same results of the ridge waveguide T-coupler, which it's shown in figure 6.

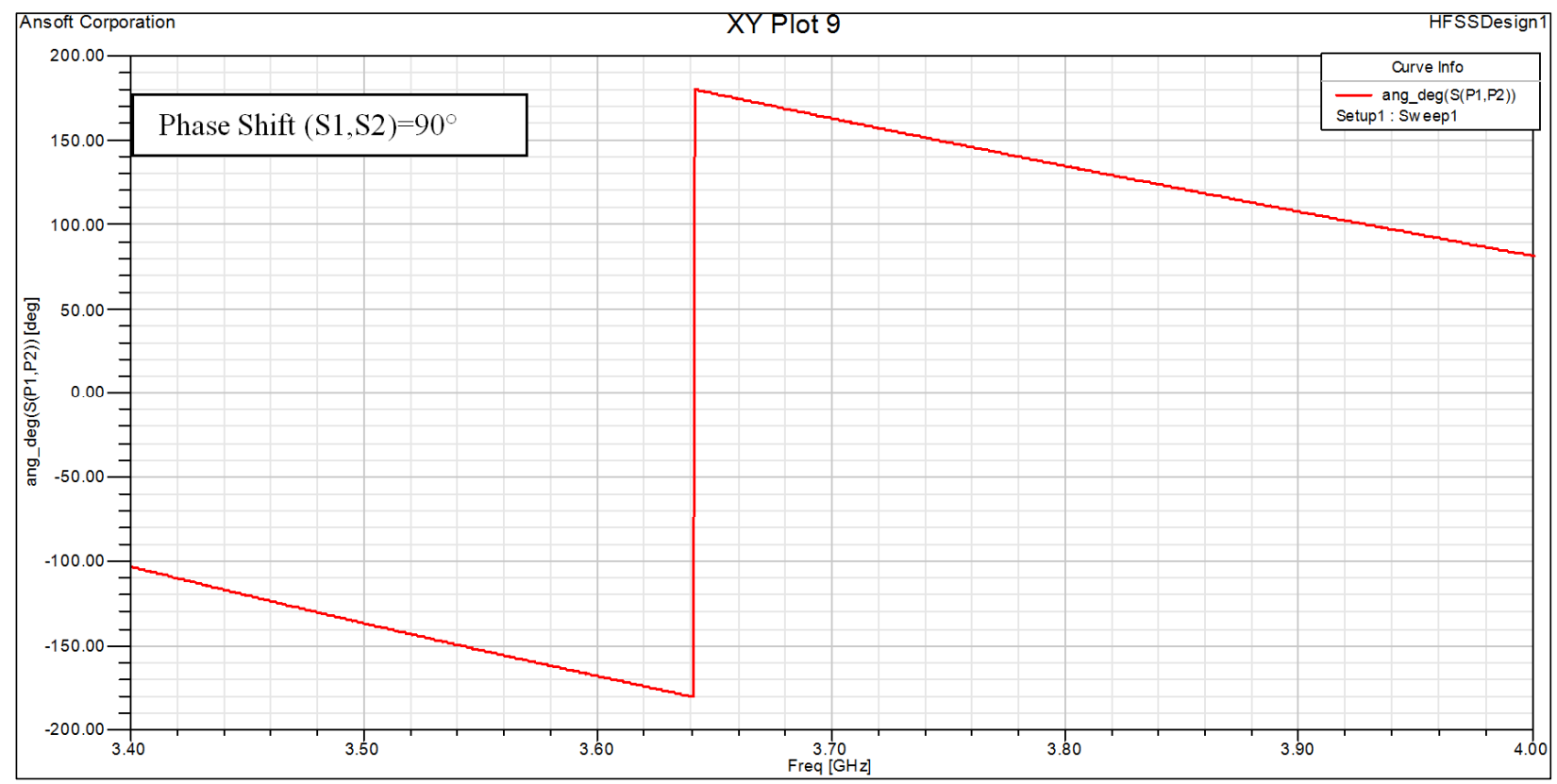

Figure 14. Phase of transmission coefficients out the co-linear ports for Magic Tee. (Phase shift (S1, S2) $\left.=90^{\circ}\right)$.

Without any matching components placed in the waveguide port of the magic tee, the return losses for each port of the magic tee has been observed in HFSS simulation software. The return loss for only port 1 is shown in figure 15 . It can also be found that for other ports also return losses are below -10 $\mathrm{dB}$. The signal entering the port 1 will not appear at port 4 , whereas the signal entering the port 4 will not appear at port 1 , so port 1 and 4 is decoupled to each other. The coefficient of transmission $\mathrm{S}_{12}$ and $\mathrm{S}_{13}$ is $-2.86 \mathrm{~dB}$. The coefficient of reflection $S_{11}$ is equal $-11 \mathrm{~dB}$. The isolation between port 1 and port 4 is below $-60 \mathrm{~dB}$ in the band from $3.4 \mathrm{GHz}$ to $4 \mathrm{GHz}$ as shown in (figure 15) for magic-tee structure.

The comparison of different results of double ridge crosswaveguide directional coupler structure, they illustrate that the coefficient of reflection (return loss) $S_{11}$ is below $-6.02 \mathrm{~dB}$ in the port 1 . The coefficient of transmission $\mathrm{S}_{12}, \mathrm{~S}_{13}$ is below $-6.02 \mathrm{~dB}$ and the coefficient of isolation $\mathrm{S}_{14}$ is also to equal at $-6.02 \mathrm{~dB}$ in the band from $3.4 \mathrm{GHz}$ to $4 \mathrm{GHz}$ as shown in figure 4 . It is noted that the various ports of one it same coefficient of transmission which is equal to $-6.02 \mathrm{~dB}$.

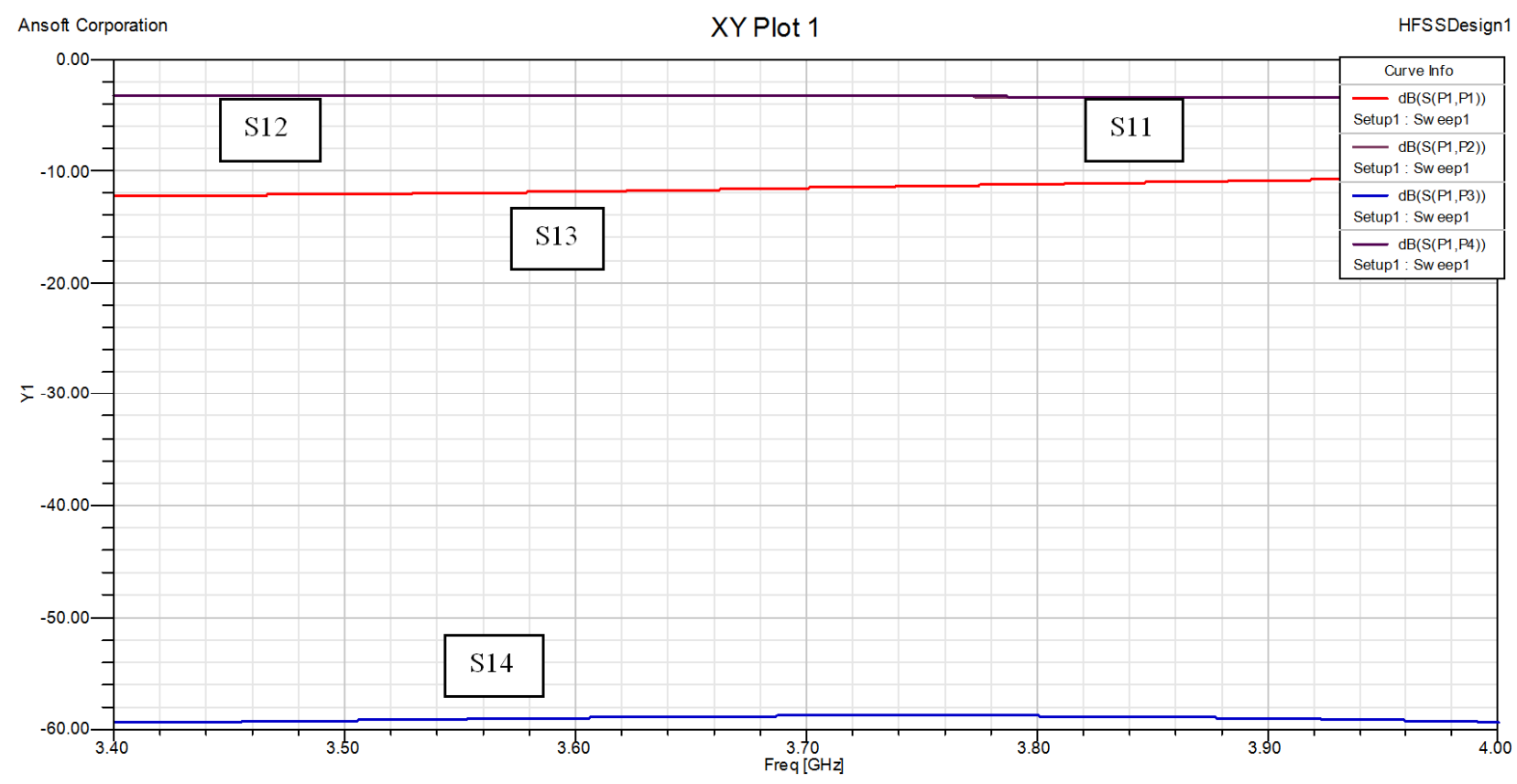

Figure 15. Different S-parameters for Magic Tee coupler. 
As it's mentioned above, the obtained results by the "AGs" are accurate and satisfactory, but the optimization procedure takes a very important computational time.

An approximate determination of the dominant-mode fields in ridge waveguides at all frequencies has been made. Evaluations of the fields along the walls of a commercially standard double-ridge guide having a usable frequency range from 3.5 to $6 \mathrm{GHz}$ were carried out, and graphs drawn so that the results could be applied to practical situations. The graphs were used to design some ridge waveguide directional couplers. Both cross-waveguide and broad-wall couplers were made in single-ridge waveguides and in double-ridge waveguides, using cross sections approximating those of the above commercially available ridge guides.

\section{Conclusions}

These couplers have been designed to handle high power. Like conventional double ridge cross-waveguide bidirectional coupler, these devices can be used as $3 \mathrm{~dB}$ power combiners, $3 \mathrm{~dB}$ power dividers, or as phase combiners. One ridge cross-waveguide bidirectional coupler is a tow way combiner, and multiple couplers can be joined to form 4,8 and higher order combiners.

\section{References}

[1] Nour EddineBoukli Hacene, J. Sombrin, A. Papiernik «Approximation by Gegenbauer polynomials in the study of a rectangular ridged waveguide. Application to the analysis of a waveguide septum polarizer». International journal of numerical modeling: Electronic Networks. Devices and Fields IJNM 2003, V16, pp299-318.

[2] Jean. Helszajn «Ridge waveguide and passive microwave components». IEE-Electromagnetic Waves Serises 49, The Institution of Electronical Engineers, juin 2000.

[3] Désiré. Lillonga-Boyenga «Contribution à la nouvelle formulation vibrationnelle: Application aux études des discontinuités et des filtres en guides d'ondes métalliques», Thèse de Doctorat, Institue National Polytechnique de TOULOUSE, École doctorale: G. E. E. T. 10 Novembre 2005.

[4] Jun. Wu. Tao, Al «A modified transverse-resonance method for the analysis of multilayered, multiconductor quasiplanar. structures with finite conductor hickness and mounting grooves». IEEE Trans. on MTT. Vol. 40, pp. 1966-1970, Oct. 1992.

[5] Goldberg David. Emanuel «Genetic algorithm search, optimization and machine learning», Addison-wesley1994.

[6] «HFSS 9: Height frequency Structure Simulator V9». Electronic Design automation Software. User's guide- Height frequency Structure Simulator. Edition: REV9.1. ANSOFT CORPORATION. 225 West Station Square. Dr Suite 200. Pitt Sburgh, PA 15219-1119. Software Version: 10. 21 June 2005.

[7] «Getting Started with Optometric. Optimizing a Waveguide. Using HFSS and Optometric». HFSS V 9.1 with optometric. May 2003.

[8] «HFSS 10: Hight frequency Structure Simulator V10». Electronic Design automation Software. User's guide- Height frequency Structure Simulator. Edition: REV 10. ANSOFT CORPORATION. 225 West Station Square. Dr Suite 200. Pitt Sburgh, PA 15219-1119. Software Version: 10. June 2006.

[9] William. Jean. Getsinger «Ridge Waveguide Field Description and Application to Directional Couplers». ISSN 0097-2002, January 2003. Published IEEE. Published in: Microwave Theory and Techniques, IRE Transactions on (Volume: 10, Issue: 1).

[10] Pompa. Debnath, S Snehasis. Roy, "An Analysis of Wave Guide Magic Tee at X-Band Using HFSS". International Journal of Emerging Technology and Advanced Engineering, (ISSN 2250-2459, Volume 2, Issue 5, May 2012).

[11] Jean. Kalia "An E-Plane Folded Magic Tee for X Band Applications". Department of Electronics and Communication Engineering National Institute of Technology Rourkel. IEEE Applied Electromagnetic Conference (AEMC), 18-20 December 2013. 